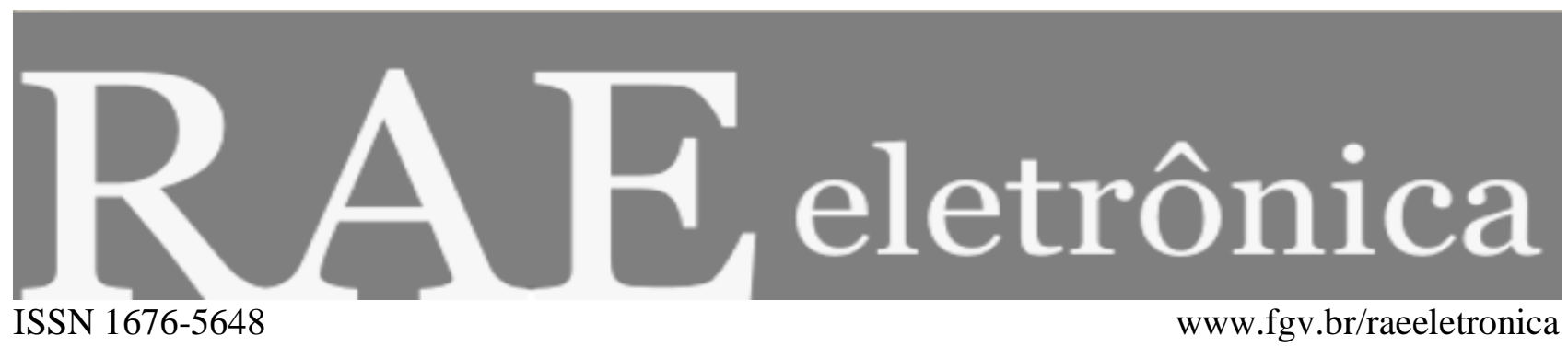

\title{
RESENHA
}

ENTENDENDO A NECESSIDADE DE RENOVAÇÃO NO PROCESSO DE ENSINO E APRENDIZAGEM

Por

\section{Marta de Campos Maia}

Professora da Escola de Administração de Empresas de São Paulo, Fundação Getulio Vargas - São Paulo - SP, Brasil

marta.maia@fgv.br

(C) Copyright 2010 FGV-EAESP/RAE-eletrônica. Todos os direitos reservados. Permitida a citação parcial, desde que identificada a fonte. Proibida a reprodução total. Em caso de dúvidas, consulte a Redação: raeredacao@fgv.br; 55 (11) 3799-7898.

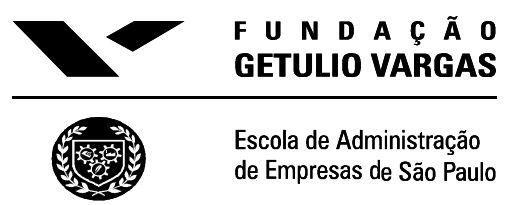




\section{INOVAÇÃO NA SALA DE AULA: COMO A INOVAÇÃO DE RUPTURA MUDA A FORMA DE APRENDER}

De Clayton Christensen, Michael Horn e Curtis Johnson. Porto Alegre: Artmed, 2009, 240 p.

O livro Inovação na sala de aula: como a inovação de ruptura muda a forma de aprender apresenta um panorama sobre a história da educação nos Estados Unidos, com foco no modelo de ensinoaprendizagem das escolas públicas; a obra é dividida em nove capítulos, trazendo casos de empresas renomadas, e contextualiza a problemática por meio de exemplos retirados do meio.

$\mathrm{O}$ livro trata do desafio de tornar o aprendizado intrinsecamente motivador para o estudante. $\mathrm{E}$ levanta algumas questões inquietantes, como, por exemplo: Por que as escolas resistem às melhorias? Será que as escolas não possuem número de computadores suficientes em sala de aula? Será que o modelo de ensino dos EUA está ultrapassado? Como fazer para atender a demanda das múltiplas inteligências e seus diferentes modos de aprendizagem em uma sala de aula? O que fazer para realizar uma inovação de ruptura nas escolas públicas nos Estados Unidos?

Administrar a inovação com eficiência é o foco dos autores, que afirmam não ser especialistas em educação, apesar de atuarem com professores há muitos anos, portanto discussões sobre modelos pedagógicos não são apresentados no texto. Analisam o setor do ensino público americano, dando ênfase às teorias de inovação pela ruptura, afirmando que a ruptura é necessária nas salas de aula e que já chega com atraso. Nesse sentido, a realidade nas salas de aula das escolas públicas americanas assemelha-se muito à realidade brasileira.

O propósito do livro é mostrar caminhos que levem à inovação no ensino, de modo a chegar cada vez mais próximo de metodologias que maximizem o potencial de aprendizagem do aluno. Discute-se o porquê do sofrimento das escolas para melhorarem, apesar do investimento de US\$ 60 bilhões, realizado pelo governo americano, para equipar as salas de aula com computadores.

Para tanto, os autores defendem a implantação da "inovação de ruptura", definida como a oferta de um serviço que ainda não tem demanda a um público de não consumidores. Essa ruptura é eficiente, pois não ataca um sistema em vigor, mas o contorna ou infiltra-se nele. Um dos exemplos citado no livro é o caso da DEC, que dominou o mercado de mainframes durante uma década, e que a Apple acabou derrubando com a criação do computador pessoal. Um produto até então sem demanda, para um público de não consumidores. As vantagens da inovação de ruptura foram amplamente detalhadas em um dos livros mais famosos de Clayton Christensen, $O$ dilema da inovação (São Paulo: Makron 
Books, 2001), no qual ele apresenta um conjunto de regras para capitalizar o fenômeno desse tipo de inovação, além de diferenciá-lo da inovação do tipo incremental.

Entretanto, os autores ressaltam que não adianta apenas usar a tecnologia centrada no aluno com o uso do computador, a ruptura se dá quando se aprende a mirar - concorrer contra o não consumo. Dessa forma, o ensino e aprendizado via computador ganha terreno quando se torna a melhor alternativa, por exemplo, no caso de um aluno fazer um curso de árabe não ofertado em sua escola, mas disponível on-line.

Analisando o sistema de ensino, surgem questões sobre os diferentes processos cognitivos de aprendizagem, e sobre as necessidades dos alunos no que se refere a ritmos desiguais para aprender. Por que então padronizamos a educação? Os autores explicam que, com a lotação das salas de aula no final dos anos 1800, o método de ensino precisou ser padronizado para atender o aumento das matrículas das escolas. Então, o que seria necessário fazer para quebrar esse paradigma? O livro sugere mudar os currículos, os testes e o processo de admissão, enfim, fazer uma grande ruptura no modelo atual de ensino. Mas bastaria inserir computadores nas salas de aula para que todo esse processo fosse alterado? Não, e por essa razão os bilhões de dólares investidos em computadores tiveram pouco efeito sobre o modo como os professores ensinam e os estudantes aprendem. Portanto, para mudar essa situação, segundo os autores, é preciso antes mudar a maneira como os professores são preparados e diplomados. Isso porque, à medida que a sala de aula mudar para a metodologia centrada no aluno, as funções dos professores também deverão sofrer transformações.

Os autores salientam que o computador emerge como uma força para essa ruptura e uma oportunidade promissora para atender à demanda das escolas em trabalhar as múltiplas inteligências dos alunos, modelos e estilos de aprendizagem distintos, já que com a utilização de tecnologias centradas no aluno pode se customizar aquilo que os estudantes aprendem. Destacam o que está errado hoje nas salas de aula: a ênfase em distribuir informação em vez de facilitar a aprendizagem por meio de atividades adequadas às necessidades e preferências dos alunos.

Defendem que o novo modelo de ensino e aprendizagem deve ter como foco principal a motivação dos alunos, que segundo os autores é o principal ingrediente da inovação de sucesso. A motivação pode ser extrínseca (quando procede do exterior da tarefa) ou intrínseca (quando o trabalho em si estimula e impulsiona o indivíduo por ser agradável e prazeroso). Por essa razão, é necessário engajar os alunos no processo de aprendizagem, levando-os a assumir a responsabilidade por seu aprendizado. As escolas precisam criar métodos intrinsecamente motivadores de ensino. 
Essa ruptura no modo de ensinar se daria em duas partes: aprendizado baseado em computador e tecnologia centrada no aluno. Os autores apontam quatro fatores que deverão apressar essa substituição: (1) o aprendizado pelo computador, que continuará sendo aperfeiçoado; (2) a transição da tecnologia baseada em computador para a centrada no aluno; (3) uma perceptível escassez de professores, indicada em pesquisas que preveem insuficiência de docentes (em 2007, 42\% dos professores nos EUA tinham mais de 50 anos); e (4) os custos terão significativa redução à medida que a escala do mercado crescer. Os dados apresentados no livro, por meio de um gráfico, ilustram uma previsão de que em 2024 cerca de $80 \%$ dos cursos existentes nos EUA serão ministrados on-line.

A pedagogia moderna afirma que o aluno deve ser estimulado a buscar soluções em grupo, por meio dos recursos de interação, para que se estimulem competências tais como as capacidades cognitivas de avaliação, análise, síntese, e não mais a simples memorização do conteúdo. Essa ideia foi proposta anteriormente por diversos autores, entre eles Piaget, Vygotsky e Freire, que afirmam que o que caracteriza a aprendizagem é o movimento de "um saber fazer" para "um saber", o que não ocorre naturalmente, mas por uma abstração reflexiva, processo pelo qual o indivíduo pensa o processo que executa e constrói algum tipo de teoria que justifique os resultados obtidos. Nesse sentido, o livro Inovação na sala de aula é muito coerente.

De forma resumida, o livro cita os princípios básicos para alcançar o sucesso na aprendizagem. Entre várias propostas, destaca a necessidade de engajar os alunos no processo de aprendizagem, levando-os a assumir a responsabilidade por sua aprendizagem; de criar e oferecer a eles diversas oportunidades e atividades de aprendizagem ativa, práticas e colaborativas, para atender aos diferentes estilos de aprendizagem. Os autores sugerem que uma nova proposta deve ser analisada para as instituições de ensino: uma alteração dos processos de ensino visando alcançar transformações na educação; para tanto, deve-se reformular toda a relação existente atualmente entre professores, alunos e currículo, visando uma educação mais dinâmica pelo uso, de forma apropriada, das tecnologias educacionais disponíveis.

A capacitação dos docentes é essencial para que ocorra efetivamente alguma inovação na sala de aula. Mas o texto não entra em detalhes sobre essa capacitação. O que normalmente se observa nas escolas brasileiras é que o foco dessa capacitação limita-se ao desenvolvimento das habilidades do professor no uso do computador, em detrimento do entendimento das possibilidades que possam ser criadas por meio da interação, da comunicação e da troca de informações entre todos os participantes.

Este é um livro voltado a qualquer leitor, tanto da área de TI quanto da área de Educação e Pedagogia, já que se preocupa com as transformações necessárias para que um ambiente educacional 
possa ser motivador, além de demonstrar a necessidade iminente de mudança no modo de ensinar, ainda que essa seja uma tarefa árdua, na qual a tecnologia é vista como uma ferramenta indispensável. Mas é necessário lembrar que muito já foi escrito e discutido sobre esse tema. Jan Amos Comenius, líder religioso tcheco, filósofo e o iniciador da pedagogia moderna, no século XVII afirmava: "É necessário desenvolver um método de ensino em que os professores lecionem menos para que os alunos possam aprender mais".

De leitura agradável, a obra desperta o tempo todo insights sobre a importância de inovar, e mostra como, por que e de que modo professores e educadores podem se engajar na melhoria do ensino. Como em outros livros sobre o tema, a conclusão é que a escola deve ser um ambiente de aprendizado agradável, motivador e cada vez mais próximo da realidade de seus alunos. 